\section{MEASUREMENT OF CHEST WALL VOLUME CHANGES BY OPTOELECTRONIC PLETHYSMOGRAPHY IN NEWBORNS DURING CPAP}

\author{
E. Zannin', M. Natile'2, R.L. Dellaca'1,
}

M.L. Ventura ${ }^{2}$, C. Veneroni', M. Colombo ${ }^{2}$, T. Fedeli ${ }^{2}$, A. Pedotti ${ }^{1}$, P. Tagliabue ${ }^{2}$

${ }^{1}$ Politecnico di Milano, Milan, ${ }^{2}$ Department of Neonatology, S. Gerardo Hospital, Monza, Italy

Background and aim: Optoelectronic plethysmography (OEP) allows the measurement of lung volume changes through the assessment of chest wall surface motion. It has been shown that it provides an accurate estimation of total and compartmental (rib cage and abdomen) lung volume changes in adults during spontaneous breathing and mechanical ventilation and in spontaneously breathing infants (REF). The aim of the present study is to evaluate the accuracy of OEP in infants during continuous positive airways pressure (CPAP).

Methods: 5 infants $(\mathrm{GA}=27.9 \pm 3.6, \mathrm{PNA}=3.8 \pm 3.6$, $B W=1077 \pm 461$ ) were studied for $\sim 2$ minutes at CPAP 0,4 and $8 \mathrm{cmH} 2 \mathrm{O}$. Flow was measured at the inlet of a full-face mask by a mesh-type pneumotacograph connected to a differential pressure transducer. Chest wall volume changes were measured by OEP (DVOEP) and compared with lung volume changes obtained by integrating the flow signal (DVPNT).

Results: We analysed a total of 602 breaths at 0 $\mathrm{cmH} 2 \mathrm{O}, 523$ at $4 \mathrm{cmH} 2 \mathrm{O}$, and 150 at $8 \mathrm{cmH} 2 \mathrm{O}$. The mean difference between DVOEP and DVPNT for all newborns was $-0.45 \pm 3.92 \%$ of $\mathrm{Vt}$ at $0 \mathrm{~cm} \mathrm{H} 2 \mathrm{O}$, $-4.25 \pm 9.04 \%$ at $4 \mathrm{cmH} 2 \mathrm{O}$ and $-8.31 \pm 3.87 \%$ at 8 $\mathrm{cmH} 2 \mathrm{O}$. Pooling data points from all infants and all pressure levels, Bland-Altman and linear regression analysis showed good agreement between the two measurement techniques (see Fig).
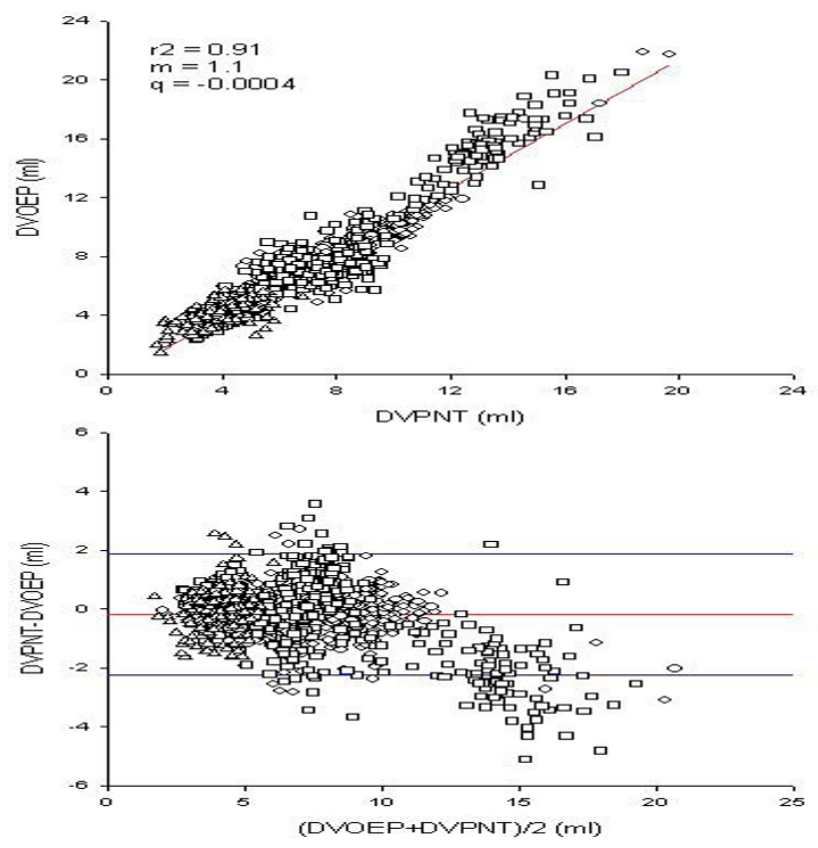

[Figure1]

Conclusions: OEP can be used to assess lung volume changes and breathing pattern noninvasively in newborns supported by CPAP.

\section{6}

\section{EXTUBATION FAILURE IN VERY LOW BIRTH WEIGHT PRETERM: INCIDENCE AND RISK FACTORS}
A. Khaldi, B. Asma, J. Borhene, A. Hamdi,
B. Sarra, B. Aida, K. Menif, N. Ben Jaballah
Children's Hospital of Tunis, Tunis, Tunisia

A high rate $(10-50 \%)$ of preterm infant, intubated shortly after birth need reintubation with associated complications (longer mechanical ventilation, hospital stay, higher mortality rate).

Objectives: identify incidence and risk factors associated with failure of extubation in very low birth weight (VLBW).

Population and methods: Retrospective study including 118 preterm infants with VLBW $\leq 1500$ grs requiring mechanical ventilation (MV) within the first 24 hours of life. Extubation failure was defined as the need for reintubation within 7 days after the first Extubation attempt.

Results: 7 patients died before the first Extubation attempt. Of the remaining 111 patients, $19(17 \%)$ failed extubation. Global mortality rate was $18,6 \%$ and was higher in the failure group than in the 